\title{
Reflexões sobre o ensinar e aprender Filosofia
}

\section{Reflections on teaching and learning Philosophy}

Ms. Ivan Luís Schwengber ivan.s@unochapeco.edu.br

Unochapecó - SC
Dndo. Jenerton Arlan Schütz jenerton.xitz@hotmail.com

Unijuí - RS

A partir da revisão bibliográfica, o presente escrito tematiza a relação entre filosofia e ensino, movimento que nos conduz à seguinte indagação: é possível aprender e ensinar filosofia? Consideramos que o ensino é um modo de comunicação ou exteriorização do pensamento, por meio do qual procuramos compartilhar algo com alguém. Não obstante, o ensino também é uma situação concreta na qual encontramos o Outro capaz de colocar todo o conhecimento em questão. Portanto, uma filosofia realmente autêntica é aquela que não pode ser separada da relação concreta do ensinar e do aprender.

PALAVRAS-CHAVE Filosofia. Ensino. Educação

From the bibliographical review, the present paper thematizes the relation between philosophy and teaching, movement that leads us to the following question: is it possible to learn and teach philosophy? We believe that teaching is a mode of communication or externalization of thought, through which we seek to share something with someone. Nevertheless, teaching is also a concrete situation in which we find the Other able to put all the knowledge in question. Therefore, a truly authentic philosophy is one that can not be separated from the concrete relationship of teaching and learning.

KEYWORDS Philosophy. Teaching. Education 


\section{Introdução}

Dificilmente podemos deixar de associar os conceitos de filosofia e ensino. Realizar a reflexão sobre a relação entre filosofia e ensino nos conduz à obrigatoriedade da seguinte indagação: é possível aprender e ensinar filosofia? Pela via kantiana, por exemplo, a resposta a esta pergunta seria "não", uma vez que a impossibilidade de tal aprendizagem se deve ao fato de que não há/existe uma única filosofia que tenha sido estável em todas as suas partes (KANT, 1992). O desenrolar dos sistemas no tempo é uma prova de que o exercício da razão pode sempre recomeçar outra vez mais.

Aprender uma filosofia significaria apenas um modo de tomar contato com um conhecimento já produzido e, por isso mesmo, cristalizado e sem vida, distante daquele que aprende. Na perspectiva kantiana, o verdadeiro filósofo, é aquele que "[...] na qualidade de quem pensa por si mesmo, tem que fazer uso livre e pessoal da razão, não um uso servilmente imitativo (KANT, 1992, p. 43). Porém, como fazer o uso livre da razão se, neste caso, não houver uma situação real de ensino e aprendizagem?

Toda exposição sistemática de ideias tem como objetivo uma exteriorização, ou seja, uma tentativa dramática de demonstrar um conhecimento possui um aspecto subjetivo ou, pelo menos, de quem o pretende possuir. A tese filosófica de Kant está inserida dentro do movimento iluminista, onde se defende a autonomia da razão humana, pois, "só se aprende a filosofar pelo exercício e uso próprio da razão" (KANT, 1992, p. 42). Antes desta maturidade intelectual do filósofo, colocamos a questão no âmbito formativo e pedagógico, se é possível ensinar a filosofia ao Outro. Assim, chegamos ao núcleo de nossa hipótese de que uma filosofia realmente autêntica é aquela que não pode ser separada da relação concreta do ensinar e do aprender.

Se, por um lado, o ensino é um modo de comunicação ou exteriorização do pensamento, por meio do qual procuramos compartilhar algo com alguém, por outro, ele é uma situação concreta na qual encontramos o Outro capaz de colocar todo o conhecimento em questão. Começa assim um novo ciclo, uma nova construção argumentativa, inicia-se, mais uma vez, a filosofia, o filosofar.

Desse modo, a partir da revisão bibliográfica, o texto que segue, tematiza a relação entre filosofia e ensino, movimento que está ancorado na interrogação: é possível aprender e ensinar filosofia? A fim de encontrarmos respostas à pergunta anterior, o estudo inicia pela tematização do ensino da filosofia; por conseguinte, aborda relação entre o ensino e a função crítica da filosofia; por 
fim, apresenta pressupostos para se pensar a relação entre o ensino da filosofia e a pluralidade humana. Portanto, objetivamos demonstrar que filosofia e ensino empreendem uma relação inseparável, e que ambas são um modo de tornar o mundo comum possível, ou seja, que permitem compreender que o pensamento é uma manifestação do humano, e não contrário.

\section{Sobre o ensino como um fim e o sistema como um meio}

Partimos da seguinte indagação: o que é, em termos gerais, uma demonstração filosófica? Uma demonstração filosófica é o ato pelo qual procuramos mostrar que aquilo que pensamos é objetivamente verdadeiro, ou seja, que as nossas opiniões são verdadeiras. Contudo, devemos mostrar a quem? Se já o sabemos, por que deveria haver demonstração? Nas palavras de Feuerbach (1973, p. 22, tradução nossa), “[...] a finalidade da demonstração é sempre o Outro ser humano, o único que poderia justificar meu desejo de provar e de ensinar o saber que possuo de modo imediato". Daí poder-se dizer que o ensino não é mera transmissão de ideias, mas uma forma de orientação a partir da qual Outrem poderá descobrir, por si mesmo, uma realidade que eu já conheço.

Se tratarmos a filosofia como um sistema fechado dentro de um conjunto doutrinário, ela não atende as exigências do encontro intersubjetivo. Por isso, a filosofia, como sistema a ser somente ensinado para fins de uso estratégico e eficiente nas diversas perspectivas da vida, invariavelmente significa traição ao seu conceito. Segundo Savater (2000, p. 31):

A dificuldade de ensinar filosofia é que esta disciplina consiste mais numa atitude intelectual do que num conjunto bem estabelecido de conhecimentos, cada um dos quais poderia ser separado sem diminuição de sua força assertiva do nome do seu descobridor. Por isso, a via pedagógica mais evidente, quase irremediável, passa pelo estudo de cada uma das grandes figuras do tarot filosófico (como quem diz, os seus Arcanos Maiores) pois a comemoração de tais exemplos da filosofia em marcha - quando bem feita - é o mais estimulante para o aluno e terreno mais seguro para o professor [...]. A recomendação kantiana de que não se deve ensinar filosofia mas sim a filosofar condensa num lema a dificuldade, mas 
não a resolve. $\mathrm{O}$ distintivo do filósofo não é arengar às massas nem sequer doutrinar grupos de estudo, mas comunicar o individualmente pensado a um interlocutor também único e irrepetível (SAVATER, 2000, p. 31).

O ensino da filosofia, no entendimento de Savater (2000), tem o aspecto fulcral de tocar outros sujeitos, no sentido de uma intensa relação intersubjetiva. E no sentido pedagógico, defende que há um grande impulso formativo quando seguimos as trilhas de grandes filósofos. Isto porque o conhecimento, para Savater (2000), não se encontra de forma solipsista no interior do eu, mas no nível da comunicação simbólica em que diferentes sujeitos se constituem.

No entendimento de Feuerbach (1973, p. 27, tradução nossa), “[...] toda exposição, toda demonstração (a exposição do pensamento é demonstração) tem por fim, em virtude de sua destinação original (e é unicamente a esta que devemos nos ater) o ato pelo qual Outrem conhece". Assim, por meio da linguagem é possível tornar comum aquilo que é meu, realizando com alguém a sociedade do nós. Um pensamento só pode ser realmente de alguém quando este puder ser partilhado com Outros. Eis o motivo que, conforme Feuerbach (1973), um indivíduo autossuficiente ser um absurdo.

A característica fundamental do ser humano é a não-indiferença, que se traduz principalmente no desejo de comunicação e na procura da verdade. Nessa direção, somente o Outro pode nos tornar certo e seguro da verdade que supostamente possuímos. Do mesmo modo, somente ele poderia dizer sim àquilo que é tão importante para nós, grosso modo, "[...] o pensamento é um pensamento verdadeiro quando o eu e o tu se unem. [...] Aquilo que une é bom e verdadeiro" (FEUERBACH, 1973, p. 24, tradução nossa).

Ademais, filosofar é uma busca pela universalização e interlocução, além disso, é o reconhecimento da presença de um Outro que é único e que pode dar sentido a essa demonstração. Porém, o problema é que a transmissão das ideias a Outrem não pode lhe dar o que tanto se espera, a saber, o conhecimento propriamente dito, uma vez que o encontro com o inteligível é algo que tem de ser feito solitariamente.

Não divergente, para Hannah Arendt (1993), é necessário se distanciar temporariamente do mundo e dos Outros para permanecer, por um momento na presença de nós mesmos, essa é a atividade do pensar. A retirada do mundo das aparências é essencial para o pensamento. O pensar parte da experiência concreta, mas necessita distanciar-se da experiência para submetê-la à reflexão, ou 
segundo Arendt, precisamos "parar para pensar" ". Esse modo de nos retirarmos do mundo diz respeito à "condição paradoxal de um ser vivo que [...] tem [...] a habilidade de pensar, que permite ao espírito retirar-se do mundo, sem jamais poder deixá-lo ou transcendê-lo" (ARENDT, 1993, p. 36).

Nesse sentido, a capacidade pode ser então anunciada: toda vez que pretendemos fazer filosofia, está em jogo uma saída de nós mesmos, uma exteriorização ou um esforço de comunicação. Mas, quando pretendemos realizar a comunicação, só podemos desejar que o interlocutor faça, por si mesmo, a experiência da descoberta. Não nos é possível dar a ele o que já sabemos, senão criar as condições para que ele próprio descubra.

A experiência filosófica é uma articulação laboriosa entre estar só ${ }^{2}$ e o desejo de comunicação. O conteúdo inteligível não pode ser transmitido de uma consciência para outra de modo direto, mesmo que seja por um processo de demonstração. Isso é estar só. Por outro lado, conceber implica um acontecimento dialógico por excelência, é já estar inserido numa cultura. No embate dos interlocutores, aquilo que se realiza é a vida da razão.

Pensar nos permite buscar significados e sentidos, para qual em outras esferas de nossa existência não seria possível, ou por não termos espaço e nem tempo. Nossa capacidade de relacionamento com os demais e a possibilidade de assumirmos a responsabilidade por aquilo que nos é comum, depende da nossa retirada temporária do mundo e do encontro com nós mesmos, ainda que isso não ocorra de forma imediata. Portanto, distanciamo-nos do mundo para buscar a compreensão da nossa experiência nele, lembramos os acontecidos e perguntamos qual é o sentido de tudo isso.

Referindo-se ao ensino de filosofia, é de suma importância descobrir uma maneira de estimular e despertar o pensamento, pois, como podemos impedir que o concreto da interlocução seja aprisionado pela linguagem cristalizada de um pensamento já sistematizado? Isso se torna possível somente se o "sistema" for tomado como meio e não com um fim. Não obstante,

[...] todo sistema, que não é reconhecido e assimilado como simples meio, limita e corrompe o espí-

1 "Nunca um homem está mais ativo do que quando nada faz, nunca está menos só do que quando a sós consigo mesmo" (ARENDT, 1993, p. 5). Cabe aqui ainda a relação com os regimes totalitários, os quais, não pensaram, já que não pararam para se perguntar sobre o sentido e o significado do que estavam fazendo, isso para com as vítimas e com o mundo.

2 Arendt (2004) diferencia o estar só (apesar de estar sozinho, estou na companhia de mim mesmo), da solidão (experiência de abandono, o que foi a essência do totalitarismo. 
rito, pois coloca o pensamento mediato e formal no lugar do pensamento imediato, original, dotado de conteúdo, matando, assim, o espírito de descoberta (FEUERBACH, 1973, p. 27, tradução nossa).

Por conseguinte, todo aquele que é ensinante fica dramaticamente ligado a uma atividade de comunicar, por demonstração, não um conteúdo inteligível, mas tão-somente o meio para se atingir esse conteúdo. Essa é a razão pela qual afirma Feuerbach (1973), um filósofo não pode jamais produzir um filósofo. A exposição filosófica, seja ela oral ou escrita, é sempre dramática, pois é apenas um meio para se atingir o universal.

Nessa direção, toda vez que a parte formal e sistemática da filosofia predominar sobre o exercício mesmo de pensar, o espírito que busca o conhecimento se vê ameaçado de paralisação. A palavra é um antídoto contra toda pretensão totalizante e fechada do conhecimento filosófico. Antes de ser a porta-voz do sistema, a palavra é o ato pelo qual o Outro pode realizar a experiência crítica do conhecimento. $\mathrm{O}$ ensino, enquanto estímulo e despertar do pensamento, é o fim mesmo da atividade filosófica.

O Outro, sem o qual não há possibilidade de demonstração e de prova, aparece também como realidade sensível e concreta que faz frente ao pensamento puro $^{3}$. Entre o pensamento puro e a inteligência sensível existe, segundo Feuerbach (1973), uma contradição que reflete o aspecto desafiador e problemático de toda situação de ensino, para ele, "o ser lógico constitui uma contradição direta, não mediatizada, chocante, como o ser da intuição intelectual empírico-concreta" (FEUERBACH, 1973, p. 36, tradução nossa).

Ademais, consideramos que o choque com a realidade que é sensível, segundo Feuerbach (1973), é algo que traduz o desafio de ensinar, pois, junto com o patrimônio teórico que é preciso compartilhar com os interlocutores numa sala de aula, existe a realidade concreta da vida, sobretudo aquela dos estudantes, como contraposição possível a toda determinação intelectual que pretendemos possuir ou defender. Um professor, antes de ser uma imitação do monólogo que a razão poderia estabelecer consigo mesma, é o referencial humano de um pensar que se realiza como refutação, isto é, como diálogo entre o mundo da teoria e a situação empírica da alteridade.

Nessa direção, o professor não é apenas um apresentador do mundo, mas

3 No caso de Feuerbach, trata-se da filosofia de Hegel. 
também representa ele diante dos recém-chegados. Como representante do mundo, sua tarefa é protegê-lo e conservá-lo, mostrando aos mais novos a sua relevância. Ademais, para Arendt (2013), as qualificações do professor consistem em seu conhecimento e sua autoridade frente aos recém-chegados reside nesse seu ofício de representante que o autoriza a introduzi-los neste lugar.

Contudo, esse atributo do professor não é arbitrário e também não se origina em sua pessoa, mas nos saberes, nos valores e nos princípios do mundo comum e da instituição escolar que ele representa (ALMEIDA, 2011). Portanto, é o lugar que ele ocupa e sua tarefa específica que lhe conferem uma autoridade que, contudo, não se estende a outras esferas para além da escola ${ }^{4}$. Destarte, podemos entender a afirmação de Arendt (2013, p. 239) quando reitera que: “[...] na educação, essa responsabilidade pelo mundo assume a forma de autoridade".

É a escola que deve apresentar aos mais novos as tradições, as histórias, suas conquistas e os conflitos, é ela que cuida do mundo que confiaremos às próximas gerações, agregando para a continuidade dele. É a partir da educação que também se acolhe os recém-chegados, que têm o direito de conhecer o mundo, de se apropriar dele para depois buscarem seus próprios caminhos e intervir naquilo que compartilham com os Outros (SCHÜTZ, 2016), este é o sentido da educação, ou seja, o seu valor intrínseco.

Ademais, se não buscarmos o sentido no fio proveniente da tradição, o pensamento se vê, assim, na difícil tarefa de encontrar o sentido sem poder contar com os padrões universais estabelecidos como tais pelo passado. A "herança sem testamento", como bem lembra Arendt (2013), remete à situação do pensamento no mundo contemporâneo e, tal estado, obriga a filosofia a se reconciliar com a existência e a buscar a sua significação no seu âmbito mesmo e não em outro mundo ou numa legalidade ou conhecimento do curso histórico no seu todo.

\section{O ensino e a função crítica da filosofia}

Se a filosofia pode ser ensinada de alguma forma, ela deve ter a capacidade de despertar a criticidade na compreensão de mundo, pois nosso conhecimento

\footnotetext{
4 Arendt distingue autoridade de certas formas de força e/ou violência. Mesmo que em ambos os casos se possa falar de uma relação hierárquica e de obediência, aquele que obedece ao mais forte o faz por medo ou por ser forçado fisicamente a obedecer, enquanto aquele que obedece à autoridade o faz por consentimento. (ARENDT, 2013). Nesse sentido, o professor pode constituir uma autoridade frente ao aluno, "[...] se ambos reconhecem a legitimidade do mundo comum e a necessidade de sua continuidade" (ALMEIDA, 2011, p. 39).
} 
é fruto de nossa experiência intelectual. Iniciamos a reflexão desta seção com a seguinte proposição: tanto o saber condensado nos textos históricos da filosofia quanto aqueles que são frutos de nossa própria atividade como professor são sempre realidades interligadas a situações anteriores/passadas. O núcleo desta seção é que o ensino é a partilha de experiências, situações e visões de mundo.

Na tradição platônica da reminiscência, conhecer é recordar. No Fedro, Platão (1975, 276a-b, p. 94) considera que "o que está dito nas obras e nos textos não pode falar por si mesmo, não se encontra no presente como algo vivo e original". Não obstante, tudo aquilo que nós consideramos "saber" encontra-se em nós como algo imediato e constitutivo, por isso, uma situação de ensino clama sempre por uma presentificação ou atualização constante. A atividade de ensino e aprendizagem é vista como recordar. Neste sentido, as palavras têm a capacidade de presentear a alma com a verdade transcendental.

A palavra possui esta capacidade de transcender ao Outro, ao ser do Outro. A palavra como representação do ensinamento é a produção mesma do presente, do mesmo modo, o falar nos representa um esforço para impedirmos que aquilo que dizemos ou pensamos seja conduzido ao passado da palavra escrita. O Outro representa a ruptura do eu, anunciando a face da comunidade, isto é, do nós. Para Lévinas (1980), a palavra pode ser chamada docência, exatamente porque se mostra como movimento de atualização constante. Toda apresentação de ideias supõe um docente, isto é, aquele que tematiza, questiona, objetiva o mundo para Outrem. O vaivém das ideias e dos pensamentos assenta no ensino ou, se preferirmos, na relação com uma fala docente.

Para Lévinas (1980) o Outro tem dimensão ética, o rosto do Outro já é uma manifestação da linguagem, é um discurso do infinitamente Outro que se abre. $\mathrm{Na}$ relação de ensino, a relação mestre e aluno é a relação de duas totalidades, que se abrem e devem encontrar um lugar comum.

Nessa direção, um dos dramas de quem ensina filosofia é saber de onde começar. Geralmente nos deparamos com perguntas do tipo: Qual livro devo usar/ escolher? Como vou montar o programa de estudos? Que autores devo utilizar/ privilegiar? O conhecimento filosófico, por mais rigoroso que possa ser, depende sempre de um princípio de orientação para constituir-se enquanto saber. A origem não poderia surgir do amontoado bruto dos fatos, segundo Lévinas (1980), e neste ponto consideramos que ele se encontra muito próximo de Feuerbach e Arendt, quando afirma que docente é aquele que oferece o mundo a alguém.

O saber objetivo poderá apresentar-se como problema significativo no momento em que acolhemos um mestre, isto é, uma fala docente. O trabalho de 
docência se identifica, assim, como uma espécie de atualização do presente, que põe fim ao amontoado caótico dos fatos, essa atualização pode ser denominada de situação de ensino.

Referindo-se à situação de ensino, o mestre não é identificado ao indivíduo titulado, que trabalha em uma dada instituição. Trata-se de uma situação fenomenológica por excelência, na qual o Outro é sempre aquele que pode fazer face e, portanto, ensinar. Por que poderia fazê-lo? Pelo fato de encontrar alguém como docente implica, necessariamente, em descobrir a franqueza de um face a face, uma espécie de retidão sem a qual o mundo humano seria impossível e impraticável.

Não obstante, se não houvesse a situação concreta da docência, a filosofia não poderia distinguir-se da retórica. $\mathrm{O}$ desejo de convencer alguém, mesmo que seja ao preço de uma maquinação eticamente reprovável, supõe a retidão do olhar docente. Daí podemos afirmar que o pensamento não se resume a uma cadeia de raciocínios supostamente verdadeiros, que dispensa a relação intersubjetiva. A vida filosófica requer indivíduos humanos concretos, que podem sempre fazer face uns aos Outros. Pensamos que, na ausência da fala docente, a filosofia se transforma em amontoado de teorias, concordantes ou não entre si. Seus cultivadores, por sua vez assemelhar-se-iam a personagens de uma trama mitológica, perdendo sua identidade desde o início da narrativa.

$\mathrm{Na}$ sala de aula, frequentemente nos comportamos como reconstrutores de sistemas de pensamento. Esse trabalho é legítimo e essencial ao pensar, devendo inclusive ser objeto de nossas pesquisas educacionais. Mas o ensino de filosofia se esgota nesta noção? Devemos nos submeter ao encadeamento anônimo das proposições, como se essa fosse a única maneira de escapar da ingenuidade e da retórica? Pois bem, a docência é a situação intersubjetiva no interior da qual o confronto de ideias pode começar. Por ser a fala que fornece a orientação primeira, a docência permite, por isso mesmo, construir as condições necessárias para que o debate possa acontecer, dando continuidade à vida da razão.

Com isso, queremos salientar que a situação de ensino é aquela que causará uma distância profunda entre os interlocutores, em que o Outro é completamente outro, numa radical alteridade tal noção é explicada por Lévinas (1980, p. 45):

A relação de linguagem supõe a transcendência, a separação radical, a estranheza dos interlocutores, a revelação do Outro a mim. Dito de outro modo, a linguagem se fala onde a comunidade entre os termos da relação está ausente, onde falta, ou apenas se deve constituir, o plano comum. 
Temos, desse modo, duas situações que se encontram de modo conflitivo e criador. Primeiro, a ordem no caos dos fatos, a atualização do presente como docência. Por conseguinte, a constatação de uma distância que compromete toda participação num plano comum. O pensar aí se inicia no encontro com o Outro, pois, sem este encontro não haveria ensino, uma vez que a razão não poderia se manifestar como exame de ideias ou confronto de perspectivas.

O objetivo do ensino de filosofia, que começa com o desejo da partilha e do oferecimento de meu/nosso mundo a alguém (recém-chegados), anuncia-se também como tensão de linguagem, isto é, como relação intersubjetiva na qual os interlocutores poderão realizar a descoberta do novo, numa espécie de abertura para o futuro.

Não diferente de Feuerbach, Lévinas (1980) nos propõe que a vida de pensamento não seja um ato solitário, mas sim o resultado da situação concreta de ensino. É porque meu mundo pode ser compartilhado com Outrem que há objetivação e tematização. A preocupação central de Lévinas é manter o Outro em sua singularidade, não reduzindo-o ao meu eu. Mas essa possibilidade existe pelo fato de o Outro já ser reconhecido como o diferente de mim, como aquele a quem desejo comunicar ou demonstrar algo. Toda intenção de generalização e todo o esforço para abstrair pressupõem a situação de ensino.

Conforme Lévinas (1980) o problema da linguagem geral e abstrata, não pode supor a objetividade como constituída: o objeto geral não é um objeto sensível, mas aquele que somente é pensado numa intenção de generalidade e de idealidade. A linguagem é universal porque oferece coisas minhas a Outrem. Falar é tornar o mundo comum, criar lugares comuns. A linguagem não se refere à generalidade dos conceitos, mas lança as bases de uma posse comum (LÉVINAS, 1980).

Com isso, consideramos que o ensino é uma espécie de fio articulador entre o desejo de tornar algo comum e o dilaceramento trazido pela distância de um mestre. É então que podemos compreender por que, em se tratando de filosofia, são fundamentais a resistência da dúvida e a elaboração do discurso crítico.

Afirmamos fio articulador pois a fala docente é aquela que permite a análise e exposição de ideias, mas é também aquela que justifica a crítica do pensamento já produzido. Por isso, Arendt (1993, p. 69) afirma que o pensamento seria como o mito de Penélope, uma vez que: "o pensamento é como a teia [...], desfaz-se toda manhã o que se terminou de fazer na noite anterior" e, dessa forma, é a atividade do pensar e o ato de comunicar que devem prevalecer, uma vez que, devemos pensar como se nunca alguém tivesse pensado antes, comunicar como se nunca alguém tivesse comunicado antes. 
O confronto entre os grandes sistemas depende, de certo modo, das situações muitas vezes prosaicas de nossas salas de aula, de nosso esforço para traduzir, com palavras ou textos, aquilo que outros pensaram. Ao fazermos isso, nós estamos nos questionando, uma vez que a situação de ensino é o sentido de todo o questionamento filosófico e, enquanto tal, é a condição da criação e abertura do novo.

A filosofia tem o aspecto crítico, sempre está ligada ao projeto existencial dos sujeitos envolvidos, e está diretamente ligada à forma como esses sujeitos se situam no mundo. Este ponto de partida fenomenológico é sempre uma noção intersubjetiva: um "ser-com-outro", que se converte num Ser-Nós. Neste comprometimento radical, o ensino de filosofia tem o seu aspecto ético de libertação do outro. "Lévinas prescreve para ética uma função crítica no interior de toda a filosofia. A filosofia através da entrada em cena do Outro terá que questionar o sistema hermético" (SIDEKUN, 2015, p. 212). Nesta relação educativa ética, surge a possibilidade de uma nova relação baseada na solidariedade radical.

\section{O ensino da filosofia e a pluralidade}

Na situação de ensino, a relação entre os interlocutores precede e dá sentido à passagem do singular concreto ao universal do conceito. Entretanto, enquanto face a face irredutível ao próprio universal constituído, o ensino é também a condição para que o amontoado dos fatos receba um princípio, uma orientação. Ensinar é uma espécie de ruptura, um novo (re)começo. Daí poder-se dizer que os interlocutores devem permanecer afastados um do outro para que o discurso proferido não concorra para integrar as diferenças existentes no mundo comum da linguagem.

O ensino é, a um só tempo, condição da universalização e resistência à universalização, eis por que a fala docente significa, do ponto de vista filosófico, um existir sob a forma de pluralidade. Com isso, podemos considerar que há ensino quando o mundo comum construído não envolve magicamente os indivíduos. Mágico, no ensino, é o fato de que não sou capaz de controlar os resultados da busca do conhecimento, isto é, não posso controlar o prolongamento do que, de certo modo, eu próprio ajudei a criar. A categoria fundamental do ensino é, portanto, a fecundidade e não a unidade, para Lévinas (1980), o ensino é a maneira pela qual a verdade se produz sem que ela seja minha obra, sem que eu possa extraí-la de minha interioridade. A verdade expressa pela filosofia, 
consiste no desvelamento do ser frente ao olhar do Outro. A verdade é dada nesta relação.

Nesse sentido, não significa que devemos assumir uma atitude simplesmente passiva e irresponsável diante de nossos educandos, pois o problema é exatamente que, na situação de ensino, podemos nos descobrir a nós mesmos como capazes de produzir a diferença, de gerar um ser cujo destino será inteiramente diferente do nosso. Na perspectiva arendtiana, é fundamental que a pluralidade não desconsidere o reconhecimento da igualdade e da distinção, pois se não fossem iguais, os homens não poderiam compreender uns aos outros, pois a pluralidade humana tem o duplo aspecto de igualdade e diferença. Ainda, se não fossem iguais, os homens seriam incapazes de se compreender entre si e os seus ancestrais, ou de fazer planos para o futuro e prever as necessidades das gerações vindouras. Por outro lado, se não fossem diferentes, se cada ser humano não diferisse de todos os outros que já existiram, que existem ou que virão a existir, os homens não precisariam da palavra ou da ação para se fazerem entender (ARENDT, 2010).

Porém, se como professor por profissão devo insistir sobre a aprendizagem de conceitos e teorias, se tenho como tarefa zelar pelo patrimônio dos conhecimentos historicamente produzidos pela humanidade, como posso falar em pluralidade sem destruir aquilo que permite a minha sobrevivência? Poder-se-ia dizer, então, que buscar a pluralidade é o mesmo que tentar conciliar a estrutura rígida dos conceitos com a dimensão fluida, conflitiva e até mesmo prazerosa do estudo e da linguagem?

Para Gadamer (1994, p. 93, tradução nossa), “[...] o ideal da linguagem filosófica, não é nomenclatura terminologicamente unívoca e desligada ao máximo da vida e da linguagem, mas a religação do pensamento conceptual à linguagem e à verdade global que nela está presente". Ademais, como podemos, então, promover a religação dos conceitos universais da ciência com o mundo da linguagem e cultural de que participamos? Entre o saber científico, isto é, universalmente válido, e as experiências não objetiváveis da humanidade, é preciso encontrar uma aproximação hermenêutica.

Gadamer (1998) considera que o papel do Outro não está numa suposta transcendência em relação ao conhecimento e à ciência, tal como nos propõe Lévinas (1980), mas no desafio de se pensar a partir do encontro com a diferença, ou seja, em elaborar uma sabedoria que possa fazer frente ao sistema racional de utilidade predominante hoje e à religião da economia global, despertando para o diálogo entre línguas e culturas diferentes. 
Afirmamos e enfatizamos que a relação com o Outro, tematizada por Lévinas (1980), implica algo mais do que a disposição para o diálogo, pois o ensino é uma espécie de ressurgimento da fala docente, para além de toda a objetivação e participação no todo da linguagem. Essa reincidência não é obra de nossa vontade, ela não vem de nossa escolha. A situação de ensino, que aqui descrevemos, não é uma situação artificialmente criada nas instituições escolares, mas refere-se ao ressurgimento inesperado de uma consciência de responsabilidade, que vem a partir de Outrem, e não de nossa espontaneidade ou liberdade. Por isso mesmo, a fala docente não é um diálogo, mas deve ser sempre condição de toda a abertura dialógica.

Afinal, qual a tarefa do ensino de filosofia? Primeiramente, é preciso envolver-se no mundo dos conceitos e das teorias com o propósito de elucidá-lo, interpretá-lo e inová-lo. O ensino de filosofia deve dar vida ao pensamento produzido. Por conseguinte, é preciso levar a sério a experiência hermenêutica que procura retornar à fala viva, que precede e condiciona os conceitos e as formulações teóricas, somente assim poderemos compreender, com os Outros, que o saber científico deve se aproximar de outras formas de saber.

Contudo, é importante lembrarmos de outra tarefa do ensino de filosofia, a saber, a tarefa de pensar sobre o(s) sentido(s) do ensinar e do aprender, num permanente esforço para realizar a razão da pluralidade ou da abertura ao Outro. Mais do que colocar o pensamento acima da vida, ou de privilegiar o todo da linguagem como algo que nos ultrapassa, o ensino é um tipo de relação intersubjetiva que transcende o universal do conceito e o mundo comum da linguagem, pois ele é que condiciona estas duas realidades. A escola é lugar de filosofia porque procura traduzir, mesmo inconscientemente, a situação de ensino, que transcende toda a instituição escolar.

\section{Considerações finais}

Mais do que refletirmos sobre como e por que ensinar filosofia, é preciso compreender que o filosofar é inseparável do ensino, e que o ensino, ele mesmo, é a situação filosófica por excelência: início de orientação e possibilidade crítica, a uma só vez, outrossim, filosofar é reaprender a ver o mundo.

O pensar se mantém vivo quando se alimenta das experiências, e morto quando começa a girar apenas em torno de si mesmo. Portanto, o que os mais diversos "modelos" de pensamentos tiveram em comum é justamente a procura de compreender o significado de nossas experiências. 
Filosofar é uma atividade que não tem um fim e que nos instiga a prosseguir, a procurar respostas para as questões que só podemos receber respostas provisórias. Mas, essa busca está intrinsicamente ligada à nossa capacidade de assumirmos a responsabilidade pelo mundo, pois, somente quando o mundo onde nós estamos e tudo o que acontece nele faz algum sentido para nós, ele deixa de ser um lugar inóspito e passa a ser a nossa casa, que precisa de nós para ser organizada, transformada, reformada e conservada.

A preocupação do ensino está justamente na relação entre a instabilidade do pensar e a continuidade do mundo, no qual precisamos familiarizar os novos a partir do seu legado, mesmo com a perda da tradição, ainda existe alguma coisa que necessita e merece ser preservada do esquecimento. A inseparabilidade da filosofia e do ensino exige a quebra da continuidade, ou seja, requer uma ruptura no mundo cotidiano para poder se reconciliar com ele em um novo significado. O sentido da relação filosofia e ensino surge quando estabelecemos relações intersubjetivas e, a partir da comunicação as experiências humanas dão testemunho, fazendo com que os novos possam se reconhecer e serem desafiados a pensar sobre o seu papel no mundo, pois, ter linguagem significa ter mundo.

Esperamos ter demonstrado que filosofar e ensinar são realidades inseparáveis, e que ambos são um modo de tornar o mundo comum possível, isto é, permitem compreender que o pensamento é uma manifestação do humano, e não contrário.

ARENDT, H. A vida do espírito. Trad. Antônio Abranches e Helena Martins. 2.ed. Rio de Janeiro: Relume Dumará/Ed. UFRJ, 1993.

.Responsabilidade e julgamento. Trad. Rosaura Eichenberg. Edição de Jerome Kohn. Revisão técnica de Bethânia Assy e André Duarte. São Paulo: Companhia das Letras, 2004.

.Entre o passado e o futuro. Tradução de
Mauro W. Barbosa. 7. ed. São Paulo: Perspectiva, 2013.

.A condição humana. Tradução de Roberto Raposo. Revisão e apresentação de Adriano Correia. 11. ed. rev. Rio de Janeiro: Forense Universitária, 2010.

ALMEIDA, Vanessa Sievers de. Educação em Hannah Arendt: entre o mundo deserto e o amor ao mundo. São Paulo: Cortez, 2011. 
FEUERBACH, L. Manifestes philosophiques. Trad.

Louis Althusser. Paris: PUF, 1973.

GADAMER, H. G. El giro hermenéutico. Trad. Arturo Parada. Madrid: Cátedra, 1998.

GADAMER, H. G. Verdad y método II. Trad. Manuel Olasagasti. Salamanca: Sígueme, 1994.

KANT, I. Crítitica da Razão Pura. Trad. Valério Rohden e Uno Baldur Moosburger, 2.ed. São Paulo: Abril Cultural, 1983.

.Lógica. Trad. Guido Antônio de Almeida.

Rio de Janeiro: Tempo Brasileiro, 1992.

LÉVINAS, E. Totalidade e infinito. Trad. de José Pinto Ribeiro. Lisboa: Edições 70, 1980.

PLATÃO. Fedro. Trad. Carlos Alberto Nunes. Universidade Federal do Pará, 1975.

SCHÜTZ, J. A. Educação e cidadania: reflexões à luz de Hannah Arendt. 2016. Dissertação de Mestrado. Programa de Pós-graduação em Educação nas Ciências. Universidade do Noroeste do Estado do Rio Grande do Sul (Unijuí), Ijuí/RS, 2016.

SIDEKUM. A. Lévinas e a Filosofia da Educação. São Leopoldo: Karywa, 2015.

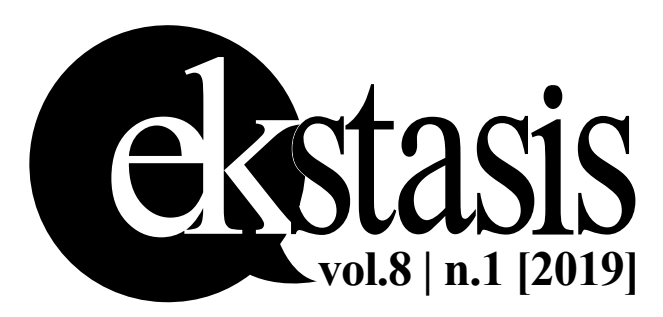

